\title{
Estratégias Pedagógicas Empregadas por Professores de Educação Especial aos seus Alunos com Deficiência Intelectual Severa: um Estudo Descritivo da Prática Docente ${ }^{1}$
}

\author{
Pedagogical Strategies Used by Special Education Teachers With \\ Students With SeVERE INTElLECTUAL Disabilities: a Descriptive StUdY of \\ TEACHING PRACTICE
}

\author{
Patricia Moralis CARAMORI ${ }^{2}$ \\ Maria Júlia Canazza DALL'ACQUA ${ }^{3}$
}

\begin{abstract}
RESUMO: esta pesquisa aborda a temática da educação de indivíduos com deficiência intelectual severa a partir das estratégias pedagógicas utilizadas por professoras de Educação Especial. Justifica-se por abordar o processo educacional de uma população pouco investigada, além de unir dois eixos de discussão de forma inovadora: a Teoria da Modificabilidade Cognitiva Estrutural (MCE) de Reuven Feuerstein e a educaçáo de alunos severamente prejudicados. Segundo essa Teoria, o professor atua como mediador, interpondo-se entre os estímulos do ambiente e o aluno. Seu objetivo pauta-se na descriçấo e análise da implementaçấo do processo educacional de alunos com deficiência intelectual severa, enfocando as estratégias pedagógicas de professoras de Educação Especial na cidade de Araraquara. Os procedimentos iniciais indicam o estabelecimento dos perfis das professoras, seu mapeamento e localização. Definidos os participantes, a coleta dos dados se deu por meio de três instrumentos: entrevista semiestruturada realizada com as professoras e observaçáo, registrada em protocolo e em diário de campo. Os dados foram analisados qualitativamente a fim de permitir a extração de detalhes do cotidiano observado. Os resultados apresentam uma descrição do trabalho das quatro professoras participantes, evidenciando suas opiniōes sobre suas práticas, além de arrolar as estratégias pedagógicas utilizadas. Oferece-se como conclusão a identificação de estratégias pedagógicas que se relacionam com os critérios que regem a mediação. Isso mostra que é possível associar as idéias de Feuerstein às práticas pedagógicas voltadas aos alunos com deficiência intelectual severa, já que determinados procedimentos empregados demonstram trazer em seu cerne alguns preceitos essenciais à mediação.
\end{abstract}

PALAVRAS-CHAVE: Educação Especial. Estratégias Pedagógicas. Prática Docente. Mediação Pedagógica.

\begin{abstract}
: this research addresses the thematic of education for individuals with severe intellectual disabilities from the pedagogical strategies used by Special Education teachers. The study is justified as it addresses the educational process of a scarcely investigated population, as well as because it combines two axes of discussion in an innovative way: Theory of Structural Cognitive Modifiability (SCM) developed by Reuven Feuerstein, and the education of severely impaired students. According this theory, the teacher acts as a mediator between the stimuli of the environment and the student. The objective is based on the description and analysis of educational process implementation of students with severe intellectual disabilities, focusing on the pedagogical strategies used by Special Education teachers in the city of Araraquara. The initial procedures included establishing the teachers' profiles, mapping and location. Once the participants were defined, data collection was carried out using three instruments: semi-structured interviews with teachers, observation recorded in protocol and in a daily logbook. Data analysis was performed qualitatively in order to allow the extraction of details from the observed routine. Results provide a description of the four participating teachers' work, revealing their views on their own practices, in addition to identifying their pedagogical strategies. As conclusion, we identify, among their actions, which ones may be related to the criteria of mediation. This study shows that associating Feuerstein's ideas to teaching practices used with students with severe intellectual disabilities is possible, as certain procedures used by the observed teachers, bring essential requirements for mediation.
\end{abstract}

KEYWORDS: Special Education. Pedagogical Strategies. Educational Practice. Pedagogical Mediation.

\footnotetext{
${ }^{1}$ http://dx.doi.org/10.1590/S1413-65382115000400004

Pesquisa subvencionada pela Coordenação de Aperfeiçoamento de Pessoal de Nível Superior (CAPES)

${ }^{2}$ Doutora em Educação Escolar pela Universidade Estadual Paulista - Unesp campus de Araraquara, Araraquara, SP, Brasil. p.caramori@uol.com.br

${ }^{3}$ Doutora em Educação Especial, Docente da Universidade Estadual Paulista - Unesp campus de Araraquara, Araraquara, SP, Brasil. juliacandal@gmail.com
} 


\section{INTRODUÇÃo}

A escolha da populaçáo se deu pelo fato de se constatar que as pessoas com deficiência intelectual severa têm sido pouco estudadas. Trabalhos de investigação que tiveram o propósito de mapear a produção de pesquisas na área da Educação Especial, nos programas de pós- graduação em Educação da Universidade Federal de São Carlos (UFSCar) e da Universidade Estadual do Rio de Janeiro (UERJ), apontam a população mais investigada como sendo aquela que apresenta deficiência intelectual (NUNES et al., 1999). Porém, quase nenhum destes trabalhos aborda como população alvo os alunos com deficiência intelectual severa ou seu processo educacional.

Um levantamento dos artigos publicados em revistas científicas levou à identificação de alguns trabalhos, em torno de 28 , mas a maioria deles tratava do indivíduo com tais características, porém sob a perspectiva, principalmente, da Medicina, da Saúde Mental, da Psiquiatria e da Psicologia. Foram poucos os que abordavam a Educação destes indivíduos.

Ao se contatar a escassez de pesquisas voltadas a esta população, torna-se importante esclarecer quem é a pessoa com deficiência intelectual severa. As concepçóes e denominaçóes variam de acordo com a evolução da ciência e da pesquisa na área da Educação, assim como o momento histórico.

A tradicional e conhecida American Association of Mental Retardation (AAMR), que alterou recentemente seu nome para American Association on Intellectual and Developmental Disabilities (AAIDD), retira o foco do indivíduo transferindo-o para a interação estabelecida a partir de seu funcionamento limitado e, também, para o ambiente no qual está inserido. Sua definição se apresenta da seguinte forma:

[...] funcionamento intelectual significativamente inferior à média [que] ocorre junto com limitações associadas em duas ou mais das seguintes áreas de habilidades adaptativas possíveis: comunicação, cuidado pessoal, vida doméstica, habilidades sociais, utilização da comunidade, autogoverno, saúde e segurança, habilidades acadêmicas funcionais, lazer e trabalho. A deficiência mental manifesta-se antes dos 18 anos (AMERICAN ASSOCIATION ON MENTAL RETARDATION, 1997).

Tal posição implica a necessidade de se planejar os apoios correspondentes à expressão de cada habilidade adaptativa. Dessa forma, a concepção mais adequada sobre os indivíduos com deficiência intelectual severa se estabelece em virtude dos apoios que lhes são necessários, caracterizados como "apoios generalizados” como explica Tamarit (1997).

Pessoas com necessidades persistentes de apoio de tipo extenso ou generalizado em todas ou em quase todas as áreas de habilidades de adaptaçáo com um funcionamento intelectual no momento presente sempre abaixo da média e, em geral, muito limitado, e com presença bastante freqüente de condutas desajustadas e/ou transtornos mentais associados. Às vezes, mas náo necessariamente, essa condição descrita pode se apresentar junto com graves deficiências sensoriais, motoras e/ou graves alteraçóes neurológicas (TAMARIT et al., 1997, p.5).

Outra maneira de se mudar o foco, tirando toda a responsabilidade pela deficiência ou dificuldade da pessoa em si, é apontada, também por Tamarit (2004), que indica outro lado da situação. Ora chamados de deficientes mentais severos ou profundos, o autor manifesta a 
idéia de que o adjetivo não cabe apenas na designação da pessoa, como é comum, mas sim nos contextos de aprendizagem no qual está inserida. O baixo funcionamento intelectual - ou simplesmente mais lento - existe, mas também é correto falar em profunda ou severa dificuldade do contexto em proporcionar a resposta educacional adequada e o apoio apropriado que permitam o progresso pessoal, social e educacional do indivíduo que necessita de um atendimento diferenciado.

Tal como a escassez de estudos, a priori, de acordo com Kassar (1999), também não é possível explicar a história da educação das pessoas com deficiências mais acentuadas por meio da legislação educacional brasileira. Talvez essa ausência de leis específicas sobre a educação dessas pessoas se dê pelo fato de terem sido consideradas por muito tempo, equivocadamente, como ineducáveis.

Atualmente, por meio da Resolução no 2, de 11 de Setembro de 2001, que institui Diretrizes Nacionais para a Educação Especial na Educação Básica no Brasil, é possível constatar uma regulamentação bastante recente acerca da escolarização dos alunos com deficiência acentuada. Tal resolução aponta a seguinte indicação:

Art. 16. É facultado às instituiçóes de ensino, esgotadas as possibilidades pontuadas nos Artigos 24 e 26 da LDBEN, viabilizar ao aluno com grave deficiência mental ou múltipla, que não apresentar resultados de escolarização previstos no Inciso I do Artigo 32 da mesma Lei, terminalidade específica do ensino fundamental, por meio da certificação de conclusão de escolaridade, com histórico escolar que apresente, de forma descritiva, as competências desenvolvidas pelo educando, bem como o encaminhamento devido para a educação de jovens e adultos e para a educação profissional (BRASIL, 2001).

Com isso, os alunos com deficiência têm seu lugar garantido dentro da legislação. Desde a implantação da Inclusão nas escolas brasileiras, eles vêm ganhando mais espaço, pois ainda no início da década de 1990, a Lei de Diretrizes e Bases da Educação Brasileira (LDB) em seu Artigo $4^{\circ}$, inciso III, incorporado à Lei 5.692/71 por meio do Relatório Amin e projeto aprovado na Câmara dos Deputados em 1993, estabeleceu que o atendimento educacional especializado, que é dever do Estado, portanto gratuito aos educandos com necessidades especiais, deve ser oferecido "preferencialmente na rede regular de ensino" (FERREIRA, 1998).

O conceito de Inclusão indica a adequação da escola para receber o aluno. São destacadas necessidades de reformulação das políticas públicas educacionais, do currículo adotado, das práticas avaliativas e da formação docente com o intuito de oferecer educação de qualidade para todos independente do seu grau de dificuldade.

Quando se fala em educação de qualidade, o termo parece vago sem as especificaçóes que o caracterizam. Porém, autores que abordam o tema da educação especial, mais especificamente os alunos com deficiências severas ou profundas, tratam a questão sob outra ótica, a da aprendizagem de qualidade. De acordo com Nind (2007):

[...] boa aprendizagem é aquela que parte do indivíduo; que tem significado para ele e que realça sua autoestima e seu poder de açáo pessoal; a boa aprendizagem é ativa e interativa; ela se ajusta ao contexto de afeto, de cultivo de relacionamentos e de comunicaçáo rica (NIND, p.111, traduçáo nossa). 
A busca pelo atendimento adequado com a, conseqüente, aprendizagem de qualidade desses alunos, leva ao referencial teórico: as idéias de Reuven Feuerstein que, por meio da Teoria da Modificabilidade Cognitiva Estrutural (MCE), apresenta como foco a Experiência de Aprendizagem Mediada (EAM) e o conceito de Mediação.

No período da 2a Guerra mundial, Feuerstein teve contato com crianças que passaram por um longo período nos campos de concentração nazistas. A partir da convivência com essas crianças, passou a acreditar e a defender o que ele denominou como modificabilidade, conceito fundamental para seu trabalho, impondo uma discordância em relação aos resultados dos testes psicométricos (QI), segundo os quais, as crianças que apresentavam baixo desempenho eram consideradas deficientes mentais. Contrapondo-se ao rótulo imposto, argumentava que este tipo de teste não fornecia informaçóes sobre o verdadeiro potencial das crianças.

O termo modificabilidade sugere uma intervenção no desenvolvimento do indivíduo ao ser definida como uma modificação estrutural no funcionamento cognitivo que vai além do percurso natural, aquele que é esperado. Ela extrapola o limite dos conhecimentos formais transmitidos pelo sistema regular de ensino, referindo-se ao uso que o indivíduo faz dos seus recursos mentais para realizar tarefas como: fazer inferências, antecipar situaçóes, tomar decisóes de maneira independente e autônoma. Refere-se à criação de novos mecanismos cognitivos que alteram a estrutura mental existente, que também se autoalteraram. Segundo Gomes (2002), a mudança é gerada por processos biológicos e maturacionais que seguem um percurso esperado dentro do desenvolvimento. Nas palavras do próprio teórico:

[...] a modificabilidade representa um afastamento notável do curso natural de desenvolvimento de um indivíduo como determinado por sua base genética e/ou neurofisiológica e/ou experiencial (FEUERSTEIN; KRASILOVSKY; RAND, 1978, p.197).

Calcada nas potencialidades do ser humano, a EAM exige a presença de um mediador, atuando como peça chave para a prática pedagógica. Este é um indivíduo mais experiente, que se interpóe entre o aprendiz e o mundo que o cerca. Isso não quer dizer que qualquer pessoa assim posicionada seja um mediador, pois ela precisa estar intencionada, já que a mediação é um processo complexo em sua definição.

Desta forma, o mediador é aquele que se interpóe entre o organismo e o mundo filtrando, organizando, selecionando e dando significado cultural aos estímulos e às experiências da vida, proporcionando o desenvolvimento adequado e aumentando o grau de modificabilidade e flexibilidade no processamento das informações (GOMES; ASSIS, 1998). O papel do mediador é de suma importância para o desenvolvimento do aluno. Sua interferência filtra, adapta, reforça ou elimina, modula e até transforma os estímulos relacionando-os com o tempo e o espaço para que eles cheguem até o aluno mediado com a qualidade e a importância necessárias para que os processos de desenvolvimento cognitivo e de aprendizagem tenham sua evolução.

Para ocorrer mediação foram determinados critérios que esclarecem seus aspectos intrínsecos. Três são fundamentais, apresentando as seguintes características: 
1. Intencionalidade e reciprocidade: são características indissociáveis, pois o mediador seleciona, filtra, interpreta e oferece os estímulos ao indivíduo mediado intencionalmente e exige uma resposta, estabelecendo uma situação recíproca. A interação não é unilateral, por isso estes dois conceitos são essenciais.

2. Transcendência: o aprendizado adquirido por meio da mediação não ocorre com o intuito de esclarecer a experiência imediata, mas sim, para que haja uma mudança cognitiva estrutural capaz de facilitar a compreensão e a organização de uma resposta a uma nova experiência ou demanda futura. Por essa razão não se remete a conteúdos, podendo ser utilizado independente do tipo de cultura na qual se está inserido.

3. Significado: atribuição de valor e sentido à experiência vivenciada, permitindo que seus objetivos tornem-se compreensíveis e válidos para o indivíduo. Refere-se a aspectos sociais e éticos. Implica uma transmissão de conhecimentos, valores e crenças de geração para geração.

Dessa forma, o papel do mediador, desempenhado de forma consistente, torna-se imprescindível para o enriquecimento da interação entre o aluno e seu meio. Um professor consciente do seu trabalho e da importância de suas açóes sobre a aprendizagem de seus alunos tem, nas mãos, a chance de potencializar suas capacidades independentemente de suas limitaçóes. Os alunos da Educação Especial deparam-se com vários obstáculos, porém muitos deles podem ser vencidos com o uso da mediação.

\section{Método}

Estabelecidos os perfis dos participantes como professores de Educação Especial e seus alunos com deficiência intelectual severa, seu mapeamento e sua localização no município de Araraquara se deram por meio do envio de ofícios aos órgáos competentes. Encontradas oito turmas dentro do perfil desejado, todas foram visitadas e quatro delas foram selecionadas como participantes da pesquisa. As professoras e os pais dos alunos foram consultados para autorizarem a permanência da pesquisadora no ambiente escolar assim como sua participação no presente estudo.

Estando todos de acordo, foi estabelecido o número de sessões de observação a serem feitas. Esta pesquisa atende os requisitos de uma abordagem qualitativa, pois apresenta características próprias deste tipo de estudo. Sob este enfoque, faz-se necessário que os dados sejam coletados diretamente no ambiente onde as situaçóes ocorrem de forma natural e Triviños (1987, p.122) salienta a "necessidade de observar os sujeitos não em situaçóes isoladas, artificiais, senão na perspectiva de um contexto social”. Neste caso específico a pesquisadora buscou uma inserção no espaço escolar, mais precisamente, dentro da sala de aula.

A abordagem qualitativa exige do pesquisador um tratamento minucioso do mundo observado e dos dados colhidos (BOGDAN; BIKLEN, 1994). Por isso, as anotaçóes provenientes da observação do contexto escolar, sobre as professoras e seus alunos, foram feitas em dois instrumentos diferentes que oferecem maior riqueza de detalhes, reforçando sua característica descritiva, sendo eles: o diário de campo e o protocolo de observação. 
Além desses dois instrumentos, foi utilizado um roteiro de entrevista semiestruturado o qual foi aplicado junto às professoras responsáveis por cada turma. Este procedimento foi efetuado depois de certo tempo de convívio entre a pesquisadora e as professoras, no intuito de conquistar a confiança delas para que se sentissem mais à vontade para conversar com alguém desconhecido. A confiança é como um facilitador, pois diferentes autores concordam que "[...] grande parte do trabalho envolve a construção de uma relação: investigador e sujeito [passam] a conhecer-se e o investigador [póe] o sujeito à vontade" (WHYTE, 1984). Uma pesquisa qualitativa permite a utilização de diferentes instrumentos de coleta de dados agregados e a entrevista busca conhecer o contexto observado por intermédio da linguagem do próprio sujeito, no caso, as concepçóes da professora sobre seu próprio trabalho.

O processo de análise se deu por meio da articulação entre as informaçóes coletadas e a teoria evidenciada no levantamento bibliográfico. De acordo com o tipo de abordagem adotada, a análise buscou tratar o processo e não o resultado do trabalho, ou seja, não esteve em questão se o trabalho das professoras é digno de aprovação ou não, mas sim, como este se deu e que tipo de contribuição ofereceu ao desenvolvimento e à aprendizagem dos alunos. Procurou-se conhecer a maneira como se estruturaram as relaçóes em favor do aluno. Com base em Minayo (1994), a análise buscou a compreensão dos dados coletados e as respostas para as questões que deram origem à pesquisa, a fim de ampliar o conhecimento sobre as estratégias pedagógicas utilizadas por professores de Educação Especial com alunos com deficiência intelectual severa.

A análise das ações das professoras participantes permitiu a identificação de estratégias pedagógicas, as quais foram definidas com a função de suporte, auxiliando a prática docente. Quando empregadas pelo professor, têm o papel de facilitar a aprendizagem do aluno. Apresentam-se em forma de açóes docentes que têm como mola propulsora a intencionalidade e tem como finalidade propiciar condiçóes favoráveis à aprendizagem dos alunos com deficiência intelectual severa.

Os dados do diário de campo foram inseridos de modo a complementar a análise dos protocolos, já que é por meio deles que se torna possível o conhecimento do contexto de cada dia de atividade. Da mesma forma, as informaçóes obtidas por meio das entrevistas também serviram como complemento das situações descritas.

\section{Resultados}

A cada uma das professoras participantes foi dado um nome fictício, sendo eles: Alice, Cecília, Fabiana e Renata. Aos seus alunos foi empregado o mesmo procedimento. A análise dos dados coletados permitiu a identificação um universo de 36 estratégias pedagógicas utilizadas pelas professoras, as quais variam desde a aplicação de instrução verbal simples até a modificação e alteração dos procedimentos didáticos estabelecidos.

$\mathrm{Na}$ ocasião da entrevista, Renata demonstra não se ver como responsável por realizar adaptaçóes em sala de aula, transferindo o ônus dessa responsabilidade para a instituição, o que revela uma visão mais estreita do que deveria ser sua função. Além disso, esta foi a professora que mais se utilizou de modelos durante as instruçóes, indicando buscar a realizaçáo das tarefas que propóe de maneira idealizada e não sua real construção, a qual ocorre por meio da aquisição gradual de habilidades por parte dos alunos. 
Transfere a "culpa" da aprendizagem lenta e de sua frustração para o aluno. Admite que "ainda tem muito que aprender" sobre seu ofício, porém esta posição ajuda a perpetuar o estigma das pessoas com deficiência intelectual severa, quando sua atuação poderia caminhar no sentido inverso. Um dado que corrobora com esta visão sobre a capacidade de aprender de seus alunos é o fato de haver dedicado maior tempo à realização de atividades pelas quais os alunos demonstraram pouco interesse. Isso permite avaliar que não há valorização das tarefas as quais eles fazem com interesse, pois revelam receber reduzido tempo de atenção por parte da professora.

Mesmo fazendo pouco uso das modificações e das alteraçóes dos procedimentos didáticos durante a realização das atividades, de alguma maneira, existe o emprego das mesmas, demonstrando incoerência entre sua fala e sua prática, pois não se vê responsável por adaptar, mas a executa em sala de aula.

Sobre as estratégias pedagógicas empregadas por Renata, houve uma grande diversificação em seu uso, tendo sido encontradas em ocasiôes distintas das tarefas, além de serem empregadas, praticamente, com todos os alunos. Renata consegue tornar proveitosos os momentos de seu emprego de acordo com a resposta que o aluno pode oferecer, como, por exemplo, considerando Rogério o único que tem condiçôes de estabelecer algum diálogo, é dele que se exige mais a réplica sobre o assunto tratado pela tarefa. Da mesma forma, pode-se apontar Rebeca como a aluna que mais recebe instrução associada a um modelo. Com isso, nota-se a atenção da professora em identificar as necessidades de cada um e atendê-las da melhor maneira. Além disso, o uso da estratégia de ajuda física, que se caracterizaria como a colaboração mais intensa da professora na realização das tarefas, foi identificada poucas vezes, somente em relação aos alunos que apresentam dificuldades que realmente exigem sua utilização, como em relação à aluna Rúbia que tem deficiência visual e Rogério que apresenta comprometimento de um de seus membros superiores.

Menciona como dificuldade a falta de uma auxiliar disponível para dividir os cuidados com o restante da turma durante a execução das tarefas individuais. Por outro lado, pode-se apontar como aspecto positivo de sua atuação, o fato de se sentir à vontade na relação e na interação com os alunos, o que ela mesma identifica como sendo uma facilidade de seu trabalho. A questão da cooperação como algo possível de se realizar, além de ser indicada como boa para seus alunos, e o incentivo de seu exercício também merecem destaque na atuação de Renata.

Alice, na ocasião da entrevista, deixa clara a frustração que sente em relação à sua turma de alunos severamente comprometidos. Como ela mesma explica, tal fato se dá pelo contexto escolar no qual está inserida. As limitações que seu trabalho sofre e as restriçóes impostas a novas propostas geram um descontentamento por parte da professora e isso leva a um processo de estagnação. Estando desestimulada, seu trabalho desacelera e, conseqüentemente, seus alunos respondem menos e, dessa forma, este processo leva ao declínio do progresso, levando ao sentimento de frustração da professora.

Declara-se um pouco acomodada, pois sabe que seria melhor para seus alunos se buscasse recursos diferenciados para ensiná-los. Também se constata que existe ausência de emprego de qualquer estratégia pedagógica em uma das atividades que oferece. O lado positivo desta situação é que a professora tem consciência de seu papel enquanto educadora. Pode não conseguir promover grandes mudanças em sua postura por conta das circunstâncias, mas sabe 
o que um professor deve fazer quando encontra adversidades em sua trajetória profissional. Isso indica que, sob outras condiçôes, poderia vir a fazer seu trabalho de outra forma.

Sobre as estratégias pedagógicas mais da metade das identificadas no trabalho da professora Alice tem sua aplicação baseada no uso da fala. A ajuda física oferecida durante o desenvolvimento do trabalho revelou que a professora sabe aproveitar uma única situação para mostrar, desenvolver, aplicar diferentes habilidades e conhecimentos demonstrando como intervir sobre as necessidades de seus alunos.

Fabiana foi a única professora que fez uso da instrução verbal associada à ajuda e a um modelo, o exemplo de introduçáo mais completo de que se tem registro, no qual se aplicam todas as ferramentas disponíveis para proporcionar ao aluno uma vivência mais intensa da atividade a ser realizada. Apesar de fornecer ao aluno a maneira mais ativa de participar do início de uma tarefa, Fabiana também é a única professora que não faz uso de qualquer modificação ou alteração dos procedimentos didáticos. Porém, há de se frisar que na ocasião da entrevista, aponta como sendo adaptação, a adição ou a retirada de atividades e conteúdos programados que se tornam difíceis de realizar mediante alguma adversidade ocorrida durante o dia de trabalho. Dedica $81 \%$ das tarefas a um mesmo aluno e, justamente, o aluno mais comprometido é aquele que menos tem registro de atividades realizadas, sendo quem menos recebe intervençóes por meio das estratégias pedagógicas utilizadas. Mas é provável que seja quem mais necessite delas.

Cecília mostra-se uma professora bastante disposta a ajudar seus alunos a progredirem, pois é a única que usa tanto a alteração quanto a modificação dos procedimentos didáticos como estratégias pedagógicas. Oferece estimulação sensorial a seus alunos, utilizando-se deste recurso com todos, independentemente do tipo de deficiência que apresentem. Preocupa-se em explorar todos seus sentidos para que compreendam aquilo que se propóe a ensinar. Demonstra ter clareza do seu papel enquanto educadora, tanto no discurso quanto na prática, estando sempre atenta às necessidades dos alunos, buscando fornecer-lhes o melhor subsídio para que aprendam. Somente Cecília se ver como participante ativa no processo de adaptação do trabalho para atender seus alunos, assumindo esta responsabilidade.

Ao declarar que observa o comportamento dos alunos e, a partir disso, regula a forma como os ensina mostra um meio de estabelecer um importante princípio da mediação: a intencionalidade e a reciprocidade. Sendo estes aspectos complementares e indissociáveis, esta professora é a única que chega o mais próximo possível da aplicação deste critério da mediação. Não adianta o professor dispor da intencionalidade se o aluno não lhe oferece a reciprocidade. Esta pode ser uma particularidade questionável sobre a viabilidade de seu emprego quando se trata de alunos com deficiência intelectual severa, que apresentam dificuldade na comunicação e na expressão. Contrariando essa tendência, Cecília demonstra como um professor de Educação Especial pode enfrentar tal obstáculo. Seus alunos, assim como a maioria dos alunos participantes desta pesquisa, também demonstram ter dificuldades em exteriorizar seus desejos. Porém, a atenção da professora, a convivência e sua dedicação em conhecê-los melhor, permitem a identificação dos feedbacks oferecidos, por mais sutis que sejam. 


\section{Discussáo}

Relacionando as estratégias identificadas com os critérios de mediação algumas considerações podem ser feitas. Todas as professoras ao fornecerem ajuda física aos seus alunos durante a realização das atividades caracterizam o emprego do critério intencionalidade e reciprocidade, pois demonstram suas intençóes aos alunos deixando claro que estáo dispostas a ajudá-los, a dar-lhes o suporte necessário para que consigam realizar aquela tarefa.

De acordo com Tébar (2011), um dos comportamentos de um mediador que caracteriza o critério de intencionalidade e reciprocidade é justamente o estabelecimento de contato visual, proximidade e contato físico. Além disso, também é identificado como tal o oferecimento de modelos de expressão e comportamento. No caso da ajuda física, a professora conduz o aluno na realização da tarefa dando suporte para que a finalize e, ao mesmo tempo, o ensina com o exemplo. Acrescentando, Mentis (1997) reforça a ideia de que, em casos como esses em que o aluno tem sérios comprometimentos cognitivos, o professor mediador é quem deve tomar a iniciativa da interação. As professoras estabelecendo o contato físico, oferecendo ajuda e conduzindo a realização da atividade dão o pontapé inicial para a interação junto a seus alunos deixando clara a intenção que têm em relação a eles. A reposta vem por meio do esforço de cada um em fazer e terminar a atividade proposta nos moldes que a professora estabelece e na busca contínua de atenção do aluno instituída no contato incessante.

O uso do recurso da estimulação sensorial, que foi empregado pelas professoras Alice e Cecília remete ao critério da mediação significado. De acordo com Gomes (2002, p.91) este princípio pode ser considerado como "a ponte entre o plano cognitivo e o plano afetivo-emocional” e isso significa que, nesse percurso, o mediador oferece ao mediado condiçóes para que ele tenha sua própria visão sobre o mundo. Explorando todas as sensaçóes que seus alunos podem ter, as professoras dão a eles os elementos necessários para que compreendam da maneira mais completa possível, o conteúdo que estão ensinando. Ensinar a ter consciência da diversidade de elementos que a vida pode ter e das diferentes formas pelas quais se pode sentir e interagir com eles é um canal extremamente rico para se explorar o critério significado dentro da ideia de experiência de aprendizagem mediada (TÉBAR, 2011). E a estimulação sensorial é um desses canais que agrega significado além de chegar até o aluno com comprometimentos mais acentuados de maneira diversificada.

Tal atuação das professoras também indica que elas fornecem aos alunos os seus próprios significados, pois lhes mostram suas maneiras de verem as coisas enquanto educadoras. Ao mesmo tempo, apuram-lhes os sentidos para que consigam interpretar os elementos que os cercam, possibilitando a formação de sua própria concepção do mundo. Mentis (2011) trabalha com a ideia de que quanto mais compreensão o aluno tiver sobre o mundo que o cerca maior capacidade e força para responder a esse universo ele terá e a prática das professoras vem fortalecer essa capacidade de resposta dos alunos.

Por último, o critério transcendência foi identificado não em uma das estratégias pedagógicas relatadas no trabalho, mas na situação de continuidade das atividades, na qual a professora evidencia para seus alunos o que está acontecendo. Ao verbalizar a relação existente entre as tarefas propostas, ou ao relembrar a tarefa anterior, mostrando a vinculação entre elas, se estabelece uma lógica que vai além do conteúdo abordado durante a atividade. Mentis 
(2011) identifica a transcendência na escola justamente quando o foco do ensino está no processo e não no conteúdo em si, interligando e integrando cada situação de aprendizagem a um contexto mais amplo de conhecimento.

Além disso, transcendência leva ao conhecimento de outros âmbitos daquilo que se ensina concretamente. Kozulim (2000) explicita como é possível isso acontecer:

Por exemplo, alimentar uma criança com um horário fixo tem um valor superficial de proporcionar-lhe nutrição e, possivelmente, ensinar-lhe a habilidade sensório-motora de manipular uma colher; sem dúvida, a mesma atividade pode ter o valor transcendental de ensinar a crianças as noções de tempo, horário, repetição de fatos similares, etc... (KOZULIM, 2000 apud GOMES, 2002, p.92).

O trecho apontado demonstra por meio de uma determinada situação como a interação da professora pode interferir no processo de aprendizagem dos alunos. $\mathrm{O}$ critério de transcendência nesse caso é caracterizado pelas ações descritas por Tébar (2011) como: o ensino da relação do todo com as partes, a criação de relações ativando suas funções cognitivas. A mediação estabelecida por ela ao relacionar as atividades e explicitar esta relação aos alunos oferece benefícios que vão além do ato mecânico de realização das tarefas, como folhear um livro, pintar uma figura com determinada cor ou tocar seu próprio corpo para conhecê-lo.

A discussão até esse momento se faz a respeito dos critérios isoladamente, pois a prática das estratégias pedagógicas das professoras participantes mostrou como é possível agregar os valores da mediação às atuaçóes em sala de aula. Por outro lado faz-se importante ressaltar que para que a mediação ocorra é necessário que os três critérios, intencionalidade e reciprocidade, significado e transcendência estejam presentes em um mesmo contexto. Desse modo, apenas uma única vez foi possível observar esse tipo de situação, na qual a professora Celina e sua auxiliar desafiam seu aluno com dificuldades motoras a se sustentar sozinho para ficar sentado e conseguir realizar a atividade de pintura. Com ajuda física apenas para controlar os movimentos das mãos durante a pintura, a conversa entre a professora e a auxiliar para com o aluno fez com que ele se esforçasse o suficiente e se mantivesse ereto na cadeira o tempo inteiro a ponto de terminar a atividade.

Neste caso os três critérios puderam ser identificados e, mesmo sem ter conhecimento da teoria de Feuerstein, a professora praticou mediação. A intencionalidade e a reciprocidade estão explicitas na expressão, no tom de voz, na postura da auxiliar e da professora quando desafiam o aluno a e equilibrar e sua resposta é clara mantendo-se todo o tempo da atividade sentado na cadeira por esforço próprio. Os objetivos das professoras são compartilhados com o aluno e isso se comprova no seu sucesso ao final da tarefa. O significado esteve presente, pois fez com que o aluno se envolvesse ativa e emocionalmente na atividade, já que conseguir se manter ereto e sustentado por si mesmo é um grande esforço para ele, além de ser uma grande conquista. Por último, a transcendência se faz presente no fato de ter havido uma seleção das informaçóes ou das açóes necessárias pra se manter equilibrado, as quais permitiram que o aluno conseguisse manter tal postura por tanto tempo. Incentivado pelo mediador, que conhece a trajetória e as práticas do aluno, o mediado retoma conhecimentos de vivências anteriores utilizando dados importantes para concretizar a ação atual.

Também é muito importante destacar um fator crucial para que se pratique a mediação: o sistema de crenças do professor. Isso inclui vários aspectos como: ter uma visão positiva 
e apreço em relação à educação; levar em consideração a intuição dos alunos; saber identificar com sensibilidade os diversos níveis de resposta que eles emitem; oferecer segurança aos alunos por ter consciência de que o professor é uma figura de referencial para eles; ter um estilo de trabalho que lhe confira uniformidade a uma determinada forma de trabalho e, por fim; coerência entre o que se diz e o que se faz (TÉBAR, 2011).

O desafio imposto na situação indica alguns desses aspectos, principalmente o do conhecimento sobre o aluno com o qual se trabalha e, com isso, saber reconhecer suas respostas a ponto de provocá-lo consciente do que ele é capaz de oferecer. Além disso, o estilo e a uniformidade vem na forma de parceria entre a professora e a auxiliar que interagem o tempo todo do período de trabalho estabelecendo harmonia no discurso e nas açóes conjuntas.

\section{Conclusóes}

A simples convivência dos alunos com deficiência no ambiente escolar náo garante a aquisição de conteúdos e habilidades, as quais só são ensinadas a partir de uma intervenção direta do professor. Por isso, a maneira como se dá a interação entre estas pessoas influencia demasiadamente a trajetória acadêmica do aluno e, até mesmo de vida. Direcionando o pensamento nesse sentido, há o estabelecimento do conceito de aprendizagem mediada dentro da sala de aula, fortalecendo as açóes docentes e, também, as possibilidades de ganhos efetivos dos alunos em relação ao seu desenvolvimento cognitivo.

Ao final da pesquisa conclui-se que a maioria das professoras participantes não pratica de maneira efetiva a mediação com seus alunos, assim como não lhes era exigido que o fizessem. Porém, a descrição das estratégias empregadas por elas permite dizer que, mesmo sem conhecimento sobre este posicionamento teórico, alguns traços que compóem a Experiência de Aprendizagem Mediada são aplicados em suas açóes. Sabe-se que dentre tantas açóes, identificar apenas uma que caracterize a mediação efetivamente é muito pouco, mas já é um resultado muito promissor, visto que nenhuma das professoras conhecia a teoria antes da pesquisa e este fato permite inferir que as açóes que caracterizam a mediação estão presentes no dia a dia do professor, basta que estas sejam organizadas e orientadas por um guia teórico que delineie o perfil de trabalho do professor.

Assim, deposita-se aqui uma esperança. Isso se dá ao constatar que a partir da atuação pedagógica real pode-se inferir que professores de indivíduos com deficiência intelectual severa, se devidamente orientados segundo os pressupostos de Feuerstein, podem colaborar efetivamente para a otimização da aprendizagem de seus alunos. A experiência de aprendizagem mediada vem contribuir para que os alunos aprendam de forma mais aprofundada a partir de suas experiências as quais são balizadas pelo professor detentor de ferramentas adequadas para isso (CUNHA; MAGALHÃES, 2011).

Deste modo, os programas de formação de professores, tanto inicial quanto continuada poderiam ser beneficiados com a introdução da temática das estratégias pedagógicas associadas à experiência de aprendizagem mediada em seus programas. Assim, contemplariam maneiras efetivas de como atuar com os alunos que apresentam maiores dificuldades no processo de aprendizagem. Além disso, tal como pode proporcionar esta pesquisa, um material voltado para a formação, tendo como base a atuação de professores, pode estimular iniciativas 
reflexivas a partir das próprias práticas. Este enfoque pode ser considerado como bastante positivo, pois o professor passa a ser incentivado a pensar suas açóes e, com isso, descobrir que tem boas contribuiçóes a oferecer.

\section{REFERÊNCIAS}

AMERICAN ASSOCIATION ON MENTAL RETARDATION. Retraso mental. Definición, clasificación, y sistemas de apoyo. Madrid: Alianza Editorial. 1997.

BOGDAN, R. C.; BIKLEN, S. K. Investigação qualitativa em educação. Porto: Porto Editora, 1994.

BRASIL. Conselho Nacional de Educação, Institui Diretrizes Nacionais para a Educação Especial na Educação Básica. Resolução No 2, de 11 de Setembro de 2001. Brasília, 2001. Disponível em: <http://portal.mec.gov.br/arquivos/pdf/resolucao2.pdf> Acesso em: 14 jul. 2015.

CUNHA, A. C. B.; MAGALHÁES, J. G. Oficina de aprendizagem mediada. Curitiba: Juruá, 2011.

FERREIRA, J. R. A nova LDB e as necessidades educativas especiais. Cadernos Cedes, Campinas, v.19, n.46, 1998.

FEUERSTEIN, R.; KRASILOVSKY; RAND, Y. Modifiability During Adolescence. In: ANTHONY, J. (Ed.). The Child and His Family: Children and Their Parents in a Changing World. London: Wiley, 1978. p.197-217.

GOMES, C. M. A. Feuerstein e a construção mediada do conhecimento. Porto Alegre: Artmed, 2002.

GOMES, C. M. A.; ASSIS, R. M. A proposta educativa de Reuven Feuerstein: modificabilidade cognitiva estrutural e aprendizagem mediada. Tema Livre, Salvador, n.15, p.4-5, 1998.

KASSAR, M. C. M. Deficiência múltipla e educação no Brasil: discurso e silêncio na história dos sujeitos. Campinas: Autores Associados, 1999.

NIND, M. Supporting lifelong learning for people with profound and multiple learning difficulties.

Support for learning, v.22, n.3, p.111-15, 2007.

MENTIS, M. Aprendizagem mediada dentro e fora de sala de aula. São Paulo: Instituto Pieron de Psicologia Aplicada, 1997.

MINAYO, M. C. S. Pesquisa social: teoria, método e criatividade. Petrópolis: Vozes, 1994.

NUNES, L. R. et al. A Pós-graduação em educação especial no Brasil: análise crítica da produção discente. Revista Brasileira de Educação Especial, Marília, v.5, n.1, p.113-125, 1999.

TAMARIT, J. et al. Las personas con retraso mental con necesidades de apoyo generalizado. I Definición. Madrid: FADEM, 1997. Manuscrito sin publicar.

TAMARIT, J. O aluno com necessidades de apoio generalizado. In: COLL, C. et al. Desenvolvimento psicológico e educação. 2.ed. Porto Alegre: Artmed, 2004. p.255-74. v.3.

TÉBAR, L. O perfil do professor mediador. São Paulo: Editora SENAC São Paulo, 2011.

TRIVIÑOS, A. N. S. Introdução à pesquisa em ciências sociais: a pesquisa qualitativa em educação. São Paulo: Atlas, 1987.

WHYTE, W. F. Learning from the field. Beverly Hills: Sage, 1984.

Recebido em: 15/10/2014

Reformulado em: 15/07/2015

Aprovado em: 15/09/2015 